\title{
MENGUKUR KESUKSESAN PENGGUNAAN SISTEM INFORMASI ENTERPRISE RESOURCES PLANNING (ERP) TERHADAP KEPUASAN PENGGUNA DAN DAMPAKNYA PADA KINERJA KARYAWAN DI PT UNISEM BATAM
}

\author{
Kiki Rohani $^{1}$ ) Shinta Wahyu Hati ${ }^{2}$ ) \\ 1)Prodi Administrasi Bisnis Terapan, Politeknik Negeri Batam e-mail: kiki_trc18@yahoo.co.id \\ 2)Prodi Administrasi Bisnis Terapan, Politeknik Negeri Batam e-mail: $\underline{\text { shinta@ polibatam.ac.id }}$
}

\begin{abstract}
The purpose of this observation is measuring to use Enterprise Resource Plannig information system towards user satisfaction and impact of employee performance in PT UNISEM Batam. The method of data collect using questionnaire method, obeservation method, and documentation method. While for data analysis of using path anaysis method. The results from this observation is level measuring Enterprise Resource Planning (ERP) AIMS and PORTAL by three variable, like as exogen variable (Information System Quality, Information Quality, Service Quality) by intervening variable (User Satisfaction) to see the impaction to endogen variable (Employee Performance).
\end{abstract}

Keywords: Employee Performance, ERP, MIS, User Satisfaction

\begin{abstract}
Abstrak
Tujuan dari penelitian ini adalah untuk mengukur kesuksesan penggunaan sistem informasi Enterprise Resources Planning (ERP) terhadap kepuasan pengguna dan dampaknya pada kinerja karyawan di PT UNISEM Batam. Metode pengumpulan data menggunakan metode kuisioner, metode obervasi, dan metode dokumentasi. Sedangkan untuk analisis data menggunakan metode analisis jalur (path analysis). Hasil dari penelitian ini yaitu pengukuran untuk mengukur tingkat kesuksesan sistem Enterprise Resources Planning (ERP) AIMS dan PORTAL melalui tiga variabel eksogen (Kualitas Sistem Informasi, Kualitas Informasi, dan Kualitas Layanan) melalui variabel intervening (Kepuasan Pengguna) untuk melihat dampaknya pada variabel endogen (Kinerja Karyawan).
\end{abstract}

Kata kunci: ERP, Kepuasan Pengguna, Kinerja Karyawan, SIM. 


\section{PENDAHULUAN}

Peran sistem informasi dalam sebuah perusahaan diibaratkan sebagai darah yang mengalir di dalam tubuh manusia, oleh karena itu sistem informasi sangat dibutuhkan untuk mendukung kelangsunganhidup perusahaan(existence). Jika perusahaan tidak memiliki sistem informasi yang memadai, maka dalam waktu tertentu perusahaan akan mengalami ketidakmampuan mengontrol sumber daya, sehingga tidak mampu bersaing dengan perusahaan lainnya (Rochaety et al., 2013).

Manfaat sistem informasi dalam dunia bisnis (organisasi) dapat meningkatkan profitabilitas maupun benefit untuk memenuhi kebutuhan semua unsur organisasinya dan dapat berorientasi untuk mempertahankan eksistensi bisnis serta dapat menghasilkan dana yang cukup memadai bagi lembaga bisnisnya, membantu menghasilkan produk maupun jasa yang berkualitas.

Gambaran sistem informasi perusahaan bisnis yang dibutuhkan di Indonesia, idealnya bagaimana para pengambil keputusan dapat dengan mudah mencari informasi sebagai bahan dalam proses pengambilan keputusan; seperti berapa jumlah sumber daya manusia yang dibutuhkan perusahaan, produk apa yang akan dihasilkan, semua itu diharapkan untuk terus membangun dan mempertahankan kinerja perusahaan baik jangka pendek maupun dalam jangka panjang.

Sistem informasi yang akan diciptakan harus seimbang antara infrastruktur sistem teknologi yang tersedia dengan kemampuan sumber daya manusianya sehingga tidak terjadi ketimpangan yang sangat jauh dan sistem informasi tidak dapat terwujud secara signifikan dalam menunjang kuantitas maupun kualitas perusahaan secara mendasar. Disamping itu kualitas sistem informasi semakin dibutuhkan oleh perusahaan khususnya untuk meningkatkan kelancaran aliran informasi perusahaan, dalam rangka memperkuat daya saing perusahaan maupun produk/jasa yang dihasilkan serta menciptakan aliansi atau kerjasama untuk meningkatkan kinerja perusahaan (Rochaety et al., 2013).

Salah satu penerapan sistem informasi manajemen dalam suatu perusahaan adalah dengan menerapkan adanya sistem ERP. ERP adalah singkatan dari "Enterprise Resource Planning" merupakan salah satu solusi untuk seluruh kebutuhan bisnis dan manajemen. ERP adalah sebuah sistem informasi yang dirancang untuk dapat mengendalikan seluruh aspek dalam perusahaan. ERP memudahkan kinerja (user) mengenai data-data perusahaan (Rochaety, et al., 2013).

Aplikasi ERP biasanya terdiri dari modul-modul seperti Marketing dan Sales, Operasional Lapangan, Produksi, Inventory Control, Procurement, Distribusi, Human Resources, Finance dan Akuntansi. Modulmodul ini berfungsi untuk mengontrol dan mendistribusikan implementasi yang bermanfaat bagi sistem informasi perusahaan.

Sistem informasi perusahaan yang baik seharusnya menciptakan integrasi data dan praktik terbaik dilingkungan perusahaan yang telah menerapkan ERP, agar mendapatkan output berupa data, dokumen, laporan maupun informasi yang baik dan membantu proses bisnis perusahaan. Secara tidak langsung penerapan sistem ERP membantu perusahaan memberikan output dokumen elektronik yang baik dilingkungan internal perusahaan. Salah satu penerapan praktik terbaik dilingkungan perusahaan adalah menerapkan sistem manajemen kearsipan elektronik, karena dalam sistem ERP didalamnya juga terdapat aktivitas pengelolaan dokumen.

Sistem ERP terbagi atas beberapa jenis salah satu jenis sistem informasi ERP yang ada adalah sistem ERP yang dibuat sendiri oleh perusahaan. Manfaat yang didapatkan perusahaan dengan membuat aplikasi ERP sendiri adalah agar dapat disesuaikan dengan kebutuhan perusahaan dan dapat dengan mudah diterapkan perusahaan.

Banyak manfaat dari sistem ERP yang dibuat sendiri oleh perusahaan, seperti biaya yang dikeluarkan jauh lebih murah dibandingkan dengan sistem ERP yang dibeli. Sistem ERP yang dibuat sendiri oleh perusahaan dengan meggunakan tenaga IT ini telah diterapkan dibeberapa perusahaan 
Kiki \&Shinta, mengukur kesuksesan penggunaan sistem informasi enterprise resources planning (erp) ...

manufaktur, salah satunya perusahaan manufaktur yang ada di Kota Batam dan telah di implementasikan di PT UNISEM sejak tahun 2000.

Pengimplemantasian sistem informasi ERP ini menggunakan sistem AIMS (Application Information Management System Unisem/nama ERP yang dibuat sendiri oleh perusahaan) dan sistem portal yang merupakan bagian dari sistem ERP perusahaan. Dari sistem ERP yang di buat sendiri oleh perusahaan, perusahaan dapat menghasilkan integrasi data, seperti : format invoice, purchase requisition, purchase order dan dokumen lain yang di inginkan oleh perusahaan tanpa harus terikat dengan format yang merepotkan pihak perusahaan.

Perusahaan ini merupakan perusahaan semikonduktor yang memproduksi IC (Integrated Circuit). PT UNISEM dapat menjalankan sistem ERP ini setelah diberi pelatihan dan pemberian buku manual pemakaian aplikasi. Tujuan di terapkan sistem informasi ERP ini salah satunya adalah untuk meningkatkan produktivitas kinerja karyawan di PT Unisem agar menciptakan keunggulan proses bisnis di perusahaan. Dalam penelitian Petter, et al., (2008) memaparkan bahwa integrasi data yang signifikan dapat diciptakan dari praktik terbaik mulai dari kualitas sistem, kualitas informasi dan kualitas layanan terhadap penggunaan sistem informasi.

Berdasarkan latar belakang yang telah diuraikan, maka penulis tertarik untuk meneliti sistem ERP yang dibuat dan diimplementasikan sendiri oleh PT UNISEM agar dapat mengetahui dan mengukur kesuksesan kualitas informasi

manajamen yang dihasilkan dan dampaknya terhadap kinerja karyawan, dengan mengangkat judul "Mengukur Kesuksesan Penggunaan Sistem Informasi Enterprise Resources Planning (ERP) Terhadap Kepuasan Pengguna dan Dampaknya Pada Kinerja Karyawan di PT. UNISEM BATAM".

\section{RUMUSAN MASALAH}

1. Sejauhmana pengaruh kualitas sistem Enterprise Resources Planning (ERP) terhadap kepuasan pengguna dan dampaknya pada kinerja karyawan di PT Unisem.

2. Sejauhmana pengaruh kualitas informasi sistem Enterprise Resources Planning (ERP) terhadap terhadap kepuasan pengguna dan dampaknya pada kinerja karyawan di PT Unisem.

3. Sejauhmana pengaruh kualitas layanan sistem Enterprise Resources Planning (ERP) terhadap kepuasan pengguna dan dampaknya pada kinerja karyawan di PT Unisem.

4. Sejauhmana pengaruh sistem informasi Enterprise Resource Planning (ERP) secara simultan dengan variabel kualitas sistem, kualitas informasi dan kualitas layanan terhadap kepuasan pengguna dan dampaknya pada kinerja karyawan di PT Unisem.

\section{TUJUAN PENELITIAN}

1. Mengetahui dan mengukur sejauhmana pengaruh kualitas sistem Enterprise Resources Planning (ERP) terhadap kepuasan pengguna dan dampaknya pada kinerja karyawan di PT Unisem.

2. Mengetahui dan mengukur sejauhmana pengaruh kualitas informasi sistem Enterprise Resources Planning (ERP) terhadap kepuasan pengguna dan dampaknya pada kinerja karyawan di PT Unisem.

3. Mengetahui dan mengukur sejauhmana pengaruh kualitas layanan sistem informasi Enterprise Resources Planning (ERP) terhadap kualitas informasi dan dampaknya pada kinerja karyawan yang diterapkan di PT Unisem.

4. Mengetahui dan mengukur sejauhmana pengaruh sistem informasi Enterprise Resource Planning (ERP) secara simultan dengan variabel kualitas sistem, kualitas informasi dan kualitas layanan terhadap kepuasan pengguna dan dampaknya pada kinerja karyawan di PT Unisem.

\section{KAJIAN PUSTAKA}

\section{Sistem Informasi Manajemen}

Dalam artikel Indajit (2008) suatu ketika Bill Gates pernah berujar bahwa," pada saatnya nanti, berbagai sumber daya 
terkait di dalam bisnis akan menjadi sebuah komoditi umum, sehingga yang akan membedakan antara satu perusahaan dengan lainnya adalah bagaimana manajemen mengelola sistem informasinya"

Dengan kata lain yang bersangkutan ingin menekankan bahwa cara perusahaan mengelola informasinya akan merupakan kunci sukses gagalnya sebuah bisnis di era modern.

Dalam Rochaety (2013) Sistem informasi manajemen merupakan perpaduan antara sumber daya manusia dan aplikasi teknologi informasi untuk memilih, menyimpan, mengolah dan mengambil kembali data dalam rangka mendukung proses pengambilan keputusan sebuah perusahaan.

Sistem informasi manajemen dalam sebuah perusahaan saat ini, diharapkan mengarah ke aplikasi yang betul-betul menunjang kegiatan perusahaan pada umumnya.

Untuk menerapkan Sistem Informasi Manajemen (SIM) yang terpadu dan memiliki kapabilitas dalam mendukung keberhasilan dunia yang signifikan, diperlukan keseimbangan sumber daya yang tersedia antar ketersediaan sumber daya manusia yang memiliki keterampilan dalam mengoperasikan teknlogi informasi seperti computer dan ketersediaan dana untuk pengadaan komputer yang sudah semakin canggih.

Oleh karena itu, dalam penerapan SIM pada sebuah perusahaan yang memiliki nilai tambah betul-betul membutuhkan persiapan yang sangat matang sehingga harapan untuk mengaplikasikan SIM dapat terwujud sesuai dengan perkembangan dunia bisnis yang dituntun masyarakat lebih marketable dan sellable.

Dilain pihak informasi yang dapat disajikan oleh SIM nantinya akan memberikan konstribusi yang sangat berharga dalam setiap proses pengambilan keputusan, seperti : informasi kebutuhan tenaga kerja, informasi pesaing, informasi produk maupun jasa yang dihasilkan dan informasi perkembangan pasar.

SIM diharapkan sangat bermanfaat tidak hanya bagi para pengambil keputusan perusahaan, tetapi sangat berguna bagi masyarakat sebagai salah satu sub sistem control society,terutama dalam proses operaasional perusahaan dan menyajikan produk-produk atau jasa yang berkualitas dan bisa dipertanggungjawaban dalam Rochaety, et al., (2013).

\section{Perkembangan Kesuksesan Model Sistem Informasi Manajemen \\ A. Keberhasilan Sistem Enterprise Resource Planning (ERP)}

Dalam penelitian Istianingsih dan Utami (2010) yang mengadopsi teori De Lone \& McLean, menyatakan bahwa Penerapan suatu sistem dalam perusahaan dihadapkan kepada dua hal, apakah perusahaan mendapatkan keberhasilan penerapan sistem atau kegagalan sistem.

Konsep keberhasilan sistem informasi merupakan suatu konsep yang digunakan dalam berbagai riset sebagai kriteria dasar untuk mengevaluasi sistem informasi.

\section{B. Kepuasan Pengguna Sebagai Ukuran Keberhasilan Sistem Informasi}

Dalam penelitian Istianingsih dan Utami (2010) yang mengadopsi teori De Lone \& McLean, menyatakan bahwa Kepuasan pemakai terhadap suatu sistem informasi adalah bagaimana cara pemakai memandang sistem informasi secara nyata, tapi tidak pada kualitas sistem secara teknik Guimaraes,Staples, dan McKeen.

Doll dan Torkzadeh mengggunakan survei terhadap 618 responden untuk meneliti mengenai user satisfaction dengan memodifikasi instrumen dan faktor analisis. Penelitiannya menghasilkan 12 item instrumen pengukuran user satisfaction atas kualitas sistem dan informasi, yang didapatkan dari pemakai akhir sistem informasi. Dua belas item yang dihasilkan tersebut, terbagi dalam lima komponen yaitu content, accuracy, format, ease of use, dan timeliness. Doll dan Torkzadeh telah membuktikan validitas dan realibilitas instrumen-instrumen ini.

Penelitian di Indonesia atas instrumen kepuasan pengguna sistem informasi 
Kiki \&Shinta, mengukur kesuksesan penggunaan sistem informasi enterprise resources planning (erp) ...

juga telah dilakukan oleh Istianingsih (2007) dan Istianingsih dan Wijanto (2008). Hasilnya menunjukkan bahwa validitas dan reliabilitas dari semua instrumen dari Doll dan Torkzadeh (1988) ini dapat diterapkan untuk penelitian di Indonesia karena memiliki validitas dan reliabilitas yang baik. Hasil pengujian mereka menunjukkan bahwa kepuasan pengguna akhir suatu sistem informasi memainkan peranan signifikan dalam menentukan penggunaan sistem aplikasi.

\section{Teori Model Kesuksesan Sistem Informasi}

Dalam jurnal Hasan, et al., (2013) memaparkan bahwa penelitian yang dilakukannya merupakan landasan dari teori De Lone \& McLean (2003), dimana

De Lone \& McLean melakukan peninjauan penelitian yang diterbitkan selama periode 1981-2003, dan menciptakan taksonomi keberhasilan IS (information system).

Berdasarkan pada ulasan yang ia paparkan dalam bukunya. Mereka mengidentifikasi enam variabel atau komponen kesuksesan sistem informasi. Enam variabel atau komponen kesuksesan itu adalah, Keberhasilan: kualitas sistem, kualitas informasi, penggunaan, kepuasan pengguna, dampak individual, dan dampak organisasi (Petter, De Lone, \& McLean, 2008).

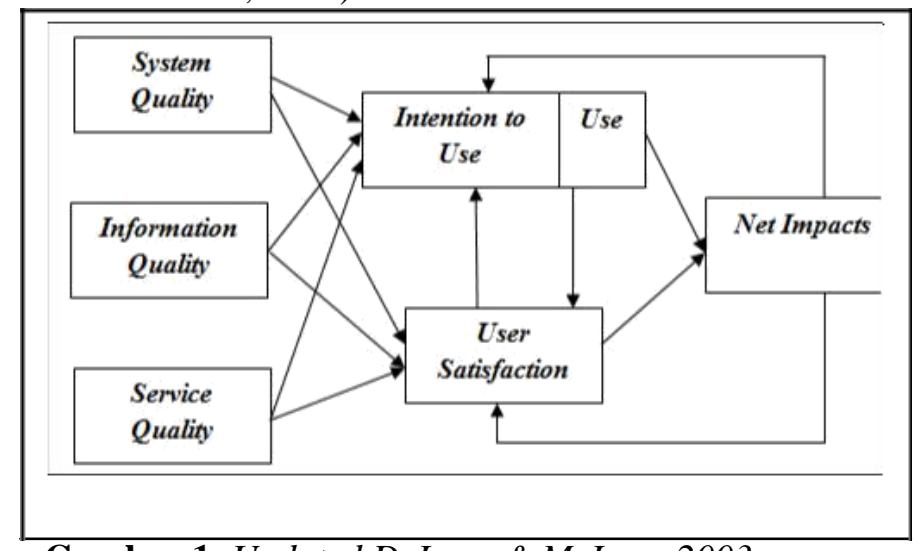

Gambar 1. Updated DeLone \& McLean 2003 IS Success Model (modified)

\section{a. Kualitas Sistem}

Karakteristik yang diinginkan dari suatu informasi sistem. Misalnya, kemudahan penggunaan, fleksibilitas sistem, sistem kehandalan, dan kemudahan belajar, serta fitur sistem intuitif, kecanggihan, fleksibilitas, dan waktu kecepatan.

\section{b. Kualitas Informasi}

Karakteristik yang diinginkan dari sistem output; yaitu, laporan manajemen dan halaman Web. Sebagai contoh, relevansi, mudah dimengerti, akurasi, keringkasan, kelengkapan, ketepatan waktu, dan kegunaan.

\section{c. Kualitas Layanan}

Karakteristik kualitas dukungan yang pengguna sistem diterima dari organisasi sistem informasi dan dukungan IT (Information Technology) personil.

\section{d. Pengguna}

Tingkat dan cara di mana karyawan dan pelanggan memanfaatkan kemampuan dari suatu sistem informasi. Sebagai contoh, jumlah penggunaan, frekuensi penggunaan, sifat penggunaan, kesesuaian penggunaan, tingkat penggunaan, dan tujuan penggunaan.

\section{e. Kepuasan Pengguna}

Tingkat pengguna kepuasan dengan laporan, Web situs, dan layanan dukungan terhadapa harapan yang melebih ekspetasi pengguna.

\section{f. Manfaat Bagi Perusahaan}

Sejauh mana sistem informasi yang berkontribusi (atau tidak memberikan kontribusi) untuk memberikan keberhasilan individu, kelompok, organisasi, industri, dan Negara. Peningkatan pengambilan keputusan, peningkatan produktivitas, peningkatan penjualan, pengurangan biaya, keuntungan meningkat, efisiensi pasar, konsumen kesejahteraan, penciptaan lapangan kerja, dan pembangunan ekonomi. 
Aplikasi praktis dari D \& M Model (2003), menjelaskan semua tergantung pada konteks organisasinya untuk penentu keberhasilan metrik perusahaannya.

\section{Kepuasan Pengguna dan Kinerja Individu}

Livari (2006), melakukan penelitian mengenai keberhasilan sistem informasi yang baru diterapkan terhadap pengguna sistem informasi di satu organisasi yang bersifat mandatory. Hasil penelitiannya untuk hubungan variabel individual impact dengan user satisfaction menunjukkan adanya pengaruh positif dari kedua variabel tersebut. Penelitian ini akan difokuskan untuk melihat sejauh mana dampak dari kepuasan pengguna sistem informasi terhadap kinerja mereka.

\section{Enterprise Resource Planning (ERP)}

Dalam Rochaety, et al., (2013).ERP adalah singkatan dari "Enterprise Resource Planning" merupakan salah satu solusi untuk seluruh kebutuhan bisnis dan manajemen perusahaan. Aplikasi ERP biasanya terdiri dari modul-modul seperti marketing dan sales, operasional lapangan, produksi, inventory control, procurement, distribusi, human resources, finance, dan akuntansi.

Sistem informasi merupakan tulang punggung informasi perusahaan. Oleh karenanya wajar apabila perusahaan mempunyai kebutuhan akan suatu sistem informasi yang mudah, handal, dan tepat guna.

\section{KERANGKA PEMIKIRAN}

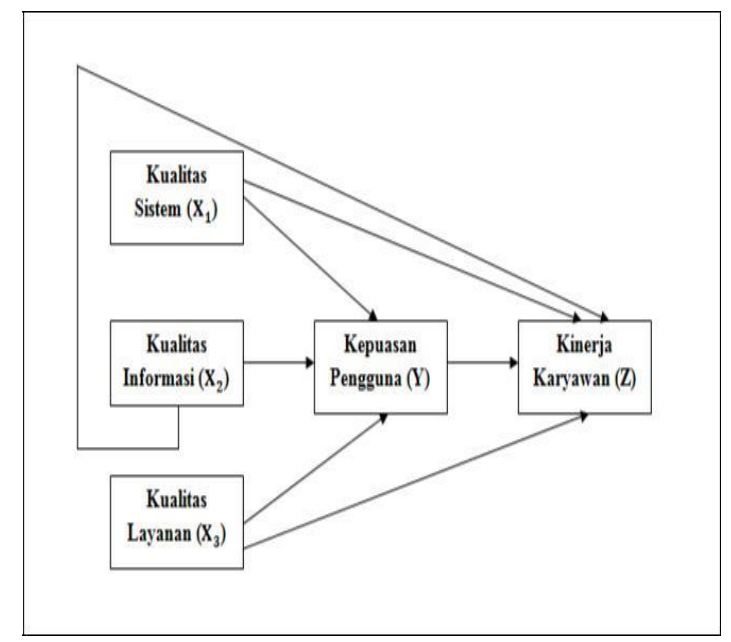

Gambar 2. Kerangka Pemikiran

\section{METODE PENELITIAN}

\section{Rancangan Penelitian}

Berdasarkan latar belakang penelitian, jenis penelitian yang digunakan adalah explanatory research. Menurut Sugiyono (2006) penelitian explanatory adalah penelitian yang bermaksud menjelaskan kedudukan variabel-variabel yang diteliti serta hubungan antara satu variabel dengan variabel yang lain.

\section{Operasionalisasi Variabel}

Variabel penelitian menurut Sugiyono (2008) adalah sebagai berikut :

1. Variabel dependen atau endogen adalah variabel yang dipengaruhi atau yang menjadi akibat karena adanya variabel independen. Variabel endogen dalam penelitiian ini adalah kinerja karyawan (Z).

2. Variabel intervening adalah variabel yang secara teoritis mempengaruhi hubungan antara variabel independen dengan dependen. Variabel intervening dalam penelitian ini kepuasan pengguna sistem informasi $\operatorname{ERP}(Y)$.

3. Variabel Independen atau variabel eksogen adalah variabel yang mempengaruhi variabel dependen atau variabel endogen. Variabel independen atau eksogen dalam penelitian ini adalah Kualitas Sistem $\left(\mathrm{X}_{1}\right)$, Kualitas Informasi $\left(\mathrm{X}_{2}\right)$, Kualitas Layanan $\left(\mathrm{X}_{\mathrm{n}}\right)$. 
Kiki \&Shinta, mengukur kesuksesan penggunaan sistem informasi enterprise resources planning (erp) ...

Tabel 1. Operasionalisasi Variabel

\begin{tabular}{|c|c|c|c|}
\hline Konsep Variabel/Sub Variabel & Dimensi & Indikator & $\begin{array}{c}\text { Skala } \\
\text { Pengukuran }\end{array}$ \\
\hline $\begin{array}{l}\text { Sistem Informasi enterprise resource } \\
\text { planning (ERP) (X) } \\
\text { merupakan salah satu solusi untuk } \\
\text { seluruh kebutuhan bisnis dan } \\
\text { manajemen perusahaan. } \\
\text { (rochaety, et all }(2013)) \backslash\end{array}$ & & & \\
\hline $\begin{array}{l}\text { Kualitas sistem }\left(\mathrm{X}_{1}\right) \\
\text { Karakteristik yang diinginkan dari suatu } \\
\text { informasi sistem. }\end{array}$ & $\begin{array}{ll}\text { 1. } & \text { Kemudahaan/Kecepata } \\
\text { n Sistem Informasi } \\
\text { 2. Keamanan Sistem } \\
\text { Informasi } \\
\text { 3. Interaksi Pengguna } \\
\text { dengan Sistem }\end{array}$ & $\begin{array}{l}\text { 1. Kehandalan sistem } \\
\text { 2. Waktu respon } \\
\text { 3. Integrasi Data } \\
\text { 4. Pengaturan sistem } \\
\text { 5. Permintaan } \\
\text { pengguna } \\
\text { 6. Adaptasi } \\
\text { 7. Bahasa } \\
\text { 8. Intuitif sistem }\end{array}$ & Skala Ordinal \\
\hline $\begin{array}{l}\text { Kualitas Informasi }\left(\mathrm{X}_{2}\right) \\
\text { Karakteristik yang diinginkan dari } \\
\text { sistem yaitu berupa output yang telah } \\
\text { dihasilkan. }\end{array}$ & $\begin{array}{l}\text { 1. Keakuratan Informasi } \\
\text { 2. Bukti Fisik } \\
\text { (Dokumentasi) }\end{array}$ & $\begin{array}{l}\text { 1.Relavansi } \\
\text { 2. Mudah Dimengerti } \\
\text { 3. Akurasi } \\
\text { 4. Kelengkapan } \\
\text { 5. Kegunaan } \\
\text { 6. Up to date }\end{array}$ & Skala Ordinal \\
\hline $\begin{array}{l}\text { Kualitas Layanan }\left(\mathrm{X}_{3}\right) \\
\text { Karakteristik kualitas dukungan yang } \\
\text { pengguna sistem diterima dari organisasi } \\
\text { sistem informasi dan dukungan IT } \\
\text { (Information Technology)personil. }\end{array}$ & $\begin{array}{l}\text { 1. Petugas Teknologi } \\
\text { Informasi }\end{array}$ & $\begin{array}{l}\text { 1. Daya Tanggap } \\
\text { 2. Empati Staff IT } \\
\text { 3. IT Trouble Shooting }\end{array}$ & Skala Ordinal \\
\hline $\begin{array}{l}\text { Kepuasan Pengguna atau user }(\mathrm{Y}) \\
\text { merupakan hasil kerja karyawan dalam } \\
\text { lingkup } \\
\text { Tingkat pengguna kepuasan dengan } \\
\text { laporan, Web situs, dan layanan } \\
\text { dukungan terhadap harapan yang } \\
\text { melebih ekspetasi pengguna. }\end{array}$ & $\begin{array}{l}\text { 1. Ekspetasi/Harapan } \\
\text { Pengguna }\end{array}$ & $\begin{array}{l}\text { 1. Kepuasan Terhadap } \\
\text { Sistem } \\
\text { 2. Kepuasan Terhadap } \\
\text { Kelengkapan } \\
\text { Informasi } \\
\text { 3. Kepuasan Terhadap } \\
\text { Layanan Staf IT }\end{array}$ & Skala Ordinal \\
\hline $\begin{array}{l}\text { Kinerja Karyawan }(\mathrm{Z}) \\
\text { merupakan hasil kerja karyawan dalam } \\
\text { lingkup tanggung jawabnya, di dalam } \\
\text { dunia usaha yang kompetensi dalam } \\
\text { tataran global, maka karyawan } \\
\text { memerlukan umpan balik atas hasil } \\
\text { kerja mereka sebagai panduan bagi } \\
\text { perilaku mereka di masa yang akan } \\
\text { datang (Suwatno dan } \\
\text { Priansa(2011:196)). }\end{array}$ & $\begin{array}{l}\text { 1. Kualitatif } \\
\text { 2. Kuantitatif }\end{array}$ & 1. Hasil Kinerja & Skala Ordinal \\
\hline
\end{tabular}




\section{Populasi dan Sampel}

Menurut Sugiyono (2008), populasi adalah wilayah generalisasi yang terdiri atas obyek/subyek yang mempunyai kualitas dan karakteristik tertentu yang ditetapkan oleh peneliti untuk dipelajari dan kemudian ditarik kesimpulannya, sedangkan sampel adalah bagian dari jumlah dan karakteristik yang dimiliki populasi tersebut.

Populasi dalam penelitian ini adalah karyawan di PT UNISEM yang bekerja memakai komputer dan menggunakan sistem informasi manajemen perusahaan, untuk menunjang proses bisnis perusahaan.

Teknik penentuan sampel adalah purposive sampling. Selanjutnya Sugiyono menjelaskan, purposive sampling adalah teknik penentuan sampel dengan pertimbangan tertentu. Maka, penentuan karakteristik sampel yang diambil adalah karyawan di PT UNISEM yang aktif menggunakan sistem informasi manajemen ERP yaitu sistem AIMS (Application Information Management System Unisem) dan PORTAL berjumlah 75 orang.

Tabel 2. Sampel Penelitian

\begin{tabular}{|c|l|c|}
\hline$N_{0}$ & Unit Kerja/Departemen & Jumlah Karyawan \\
\hline 1 & Excecutive Manajer & 2 Orang \\
\hline 2 & Purchasing Department & 8 Orang \\
\hline 3 & Human Resources Department (HRD) & 9 Orang \\
\hline 4 & Customer Services & 10 Orang \\
\hline 5 & Finance Accounting & 10 Orang \\
\hline 6 & Information Technology (IT) & 6 Orang \\
\hline 7 & $\begin{array}{l}\text { Quality Assurance (QA)/ Quality Control } \\
\text { (QC) }\end{array}$ & 10 Orang \\
\hline 8 & Facilities & 20rang \\
\hline 9 & PMC & 5 Orang \\
\hline 10 & Manufacturing & 5 Orang \\
\hline 11 & Equipment Engineering & 5 Orang \\
\hline \multicolumn{2}{|c|}{ Total Responden } & 75 rang \\
\hline
\end{tabular}

\section{Validitas dan Reliabilitas Instrumen}

\section{a. Uji Validitas}

Menurut Sugiyono (2008), uji validitas digunakan untuk mengukur apa yang seharusnya diukur. Untuk menentukan kevalidan dari masing-masing item dalam kuesioner dilakukan dengan menggunakan rumus korelasi sederhana atau pearson product moment.

Tabel 3. Rekapitulasi Hasil Uji Validitas

\begin{tabular}{|c|c|c|c|c|c|}
\hline Variabel & Item & $\begin{array}{l}\text { Nilai } r \\
\text { hitung }\end{array}$ & $\begin{array}{c}\text { Nilai } r \\
\text { Tabel }\end{array}$ & $\mid \begin{array}{c}\text { Taraf } \\
\text { Signifikansi }\end{array}$ & Kesimpulan \\
\hline \multirow{16}{*}{$\begin{array}{l}\text { Kualitas Sistem } \\
\quad \text { (X1) }\end{array}$} & X1.1.1 Mudah di akses & 0.470 & 0.227 & 0.05 & Valid \\
\hline & X1.1.2 Jaringan yang memudahkan & 0.777 & 0.227 & 0.05 & Valid \\
\hline & X1.2.3 Input \& output data cepat & 0.622 & 0.227 & 0.05 & Valid \\
\hline & X1.2.4 Kapasitas sistem memadai & 0.791 & 0.227 & 0.05 & Valid \\
\hline & X1.3.5 Komunikasi di sistem mudah & 0.582 & 0.227 & 0.05 & Valid \\
\hline & $\mathrm{X} 1.3 .6$ Distribusi data mudah & 0.660 & 0.227 & 0.05 & Valid \\
\hline & X1.4.7 Kelangkapan fitur & 0.721 & 0.227 & 0.05 & Valid \\
\hline & X1.5.8 Sistem mudah di gunakan & 0.736 & 0.227 & 0.05 & Valid \\
\hline & X1.5.9 Sistem mudah di pahami & 0.654 & 0.227 & 0.05 & Valid \\
\hline & X1.5.10 Sistem mudah di kenal & 0.705 & 0.227 & 0.05 & Valid \\
\hline & \begin{tabular}{|l|} 
X1.6.11 Fitur mudah diterapkan \\
X1.6.12 Tampilan mudah di kenal \\
\end{tabular} & 0.657 & $\frac{0.227}{0.227}$ & 0.05 & $\begin{array}{l}\text { Valid } \\
\text { Valid }\end{array}$ \\
\hline & X1.7.13 Bahasa tampilan mudah & 0.734 & 0.227 & 0.05 & Valid \\
\hline & X1.7.14 Bahasa dapat di sesuaikan & 0.630 & 0.227 & 0.05 & Valid \\
\hline & X1.8.15 Kebutuhan sistem tinggi & 0.607 & 0.227 & 0.05 & Valid \\
\hline & X1.8.16 Kerusakan Sistem & 0.460 & 0.227 & 0.05 & Valid \\
\hline & X1.8.17 Pekerjaan bergantung sistem & 0.599 & 0.227 & 0.05 & Valid \\
\hline \multirow{12}{*}{$\begin{array}{c}\text { Kualitas } \\
\text { Informasi } \\
\text { (X2) }\end{array}$} & X2.1.1 Informasi relevan & 0.667 & 0.227 & 0.05 & Valid \\
\hline & X2.1.2 Informasi lengkap & 0.809 & 0.227 & 0.05 & Valid \\
\hline & \begin{tabular}{|l} 
X2.2.3 Tampilan informasi mudah \\
\end{tabular} & 0.821 & 0.227 & 0.05 & Valid \\
\hline & X2.2.4 Informasi dapat di andalkan & 0.830 & 0.227 & 0.05 & Valid \\
\hline & X2.3.5 Output data tepat & 0.745 & 0.227 & 0.05 & Valid \\
\hline & X2.3.6 Output data akurat & 0.821 & 0.227 & 0.05 & Valid \\
\hline & \begin{tabular}{|l} 
X2.4.7 Informasi sesuai kebutuhan \\
\end{tabular} & 0.849 & 0.227 & 0.05 & Valid \\
\hline & \begin{tabular}{|l} 
X2.4.8 Informasi sangat di butuhkan \\
\end{tabular} & 0.817 & 0.227 & 0.05 & Valid \\
\hline & X2.5.9 Laporan mudah di hasilkan & 0.822 & 0.227 & 0.05 & Valid \\
\hline & X2.5.10 Laporan mudah di dapat & 0.745 & 0.227 & 0.05 & Valid \\
\hline & $\mathrm{X} 2.6 .11$ Up to date & 0.786 & 0.227 & 0.05 & Valid \\
\hline & X2.6.12 Informasi terus di perbarui & 0.838 & 0.227 & 0.05 & Valid \\
\hline Variabel & Item & $\begin{array}{l}\text { Nilai } r \\
\text { hitung }\end{array}$ & $\begin{array}{c}\text { Nilai r } \\
\text { Tabel }\end{array}$ & \begin{tabular}{|c|} 
Taraf \\
Signifikansi \\
\end{tabular} & Kesimpulan \\
\hline \multirow{6}{*}{$\begin{array}{c}\text { Kualitas } \\
\text { Layanan } \\
\text { (X3) }\end{array}$} & \begin{tabular}{|l} 
X3.1.1 Staff IT meberitahu lewat \\
sosmed
\end{tabular} & 0.786 & 0.227 & 0.05 & Valid \\
\hline & X3.1.2 Staff IT selalu membantu & 0.859 & 0.227 & 0.05 & Valid \\
\hline & X3.2.3 Staff IT perhatian & 0.810 & 0.227 & 0.05 & Valid \\
\hline & \begin{tabular}{|c|} 
X3.2.4 Staff IT memahami \\
kebutuhan
\end{tabular} & 0.953 & 0.227 & 0.05 & Valid \\
\hline & X3.3.5 Staff IT memberikan bantuan & 0.852 & 0.227 & 0.05 & Valid \\
\hline & X3.3.6 Terhubung secara on-line & 0.883 & 0.227 & 0.05 & Valid \\
\hline \multirow{4}{*}{$\begin{array}{c}\text { Kinerja } \\
\text { Karyawan } \\
\text { (Z) }\end{array}$} & Z1.1.1 Pekerjaan Capai Target & 0.836 & 0.227 & 0.05 & Valid \\
\hline & Z1.1.2 Meningkatkan Kualitas Kejja & 0.859 & 0.227 & 0.05 & Valid \\
\hline & Z1.2.3 Dapat Mempengaruhi Kinerja & 0.874 & 0.227 & 0.05 & Valid \\
\hline & Z1.2.4 Meningkatkan Kerjasama & 0.861 & 0.227 & 0.05 & Valid \\
\hline \multirow{6}{*}{$\begin{array}{c}\text { Kepuasan } \\
\text { Pengguna } \\
\text { (Y) }\end{array}$} & \begin{tabular}{|c|}
$\begin{array}{c}\text { Y1.1.1 Puas dengan kelengkapan } \\
\text { data }\end{array}$ \\
\end{tabular} & 0.760 & 0.227 & 0.05 & Valid \\
\hline & Y1.1.2 Puas dengan informasi & 0.838 & 0.227 & 0.05 & Valid \\
\hline & Y1.1.3 Puas dengan tindakan IT & 0.894 & 0.227 & 0.05 & Valid \\
\hline & Y1.1.4 Puas dengan pengetahuan IT & 0.907 & 0.227 & 0.05 & Valid \\
\hline & \begin{tabular}{|l} 
Y1.3.5 Puas dengan manfaat \\
.
\end{tabular} & 0.898 & 0.227 & 0.05 & Valid \\
\hline & Y1.3.6 Sistem sangat membantu & 0.902 & 0.227 & 0.05 & Valid \\
\hline
\end{tabular}

\section{b. Uji Reliabilitas}

Menurut Sugiyono (2008), uji reliabilitas adalah intrumen yang bila digunakan beberapa kali untuk mengukur obyek yang sama, akan menghasilkan data yang sama. Dalam penelitian ini uji reliabilitas menggunakan Cronbach Alpha.

Semakin mendekati 1 koefisien dan variabel semakin tinggi konsistensi jawaban setiap pertanyaan semakin dapat dipercaya. 
Kiki \&Shinta, mengukur kesuksesan penggunaan sistem informasi enterprise resources planning (erp) ...

Reliabilitas minimal adalah 0,60. Dengan bantuan program SPSS versi 22 for windows dapat dilakukan pengukuran reliabilitas dengan uji statistik Cronbach Alpha.Menurut Ghozali (2006) suatu konstruk atau variabel dikatakan reliabel jika nilai Cronbach Alpha $>0.60$.

Tabel 4. Rekapitulasi Hasil Uji Reliabilitas

\begin{tabular}{|c|c|c|c|}
\hline Variabel & $\begin{array}{c}\text { Cronbach } \\
\text { Alpha }\end{array}$ & $\begin{array}{c}\text { Koefisiensi } \\
\text { Cronbach } \\
\text { Alpha }\end{array}$ & Keterangan \\
\hline $\begin{array}{c}\text { Kualitas Sistem } \\
\text { (X1) }\end{array}$ & 0.759 & 0.60 & Reliabel \\
\hline $\begin{array}{c}\text { Kualitas Informasi } \\
\text { (X2) }\end{array}$ & 0.771 & 0.60 & Reliabel \\
\hline $\begin{array}{c}\text { Kualitas Layanan } \\
\text { (X3) }\end{array}$ & 0.791 & 0.60 & Reliabel \\
\hline $\begin{array}{c}\text { Kepusasan } \\
\text { Pengguna (Y) }\end{array}$ & 0.810 & 0.60 & Reliabel \\
\hline $\begin{array}{c}\text { Kinerja Karyawan } \\
\text { (Z) }\end{array}$ & 0.830 & 0.60 & Reliabel \\
\hline \multicolumn{2}{|c|}{} \\
\hline
\end{tabular}

\section{Metode Analisis Data}

\section{a. Statistik Deskriptif}

Menurut Sugiyono (2008), statistik deskriptif adalah statistik yang digunakan untuk menganalisa data dengan cara mendeskripsikan atau menggambarkan data yang telah terkumpul sebagaimana adanya tanpa bermaksud membuat kesimpulan yang berlaku untuk umum atau generalisasi.

Statistik deskriptif dalam penelitian ini digunakan untuk mengukur penggunaan sistem ERP terhadap kepuasan pengguna dan dampaknya pada kinerja karyawan yaitu karyawan PT UNISEM.

Statistik deskriptif yang di analisis dalam penelitian ini menggunakan karakteristik responden berdasarkan : Jenis kelamin, usia, pengalaman penggunaan system, pendidikan terakhir, lama pemakaian komputer, dan unit kerja.

Tabel 5. Karakteristik Berdasarkan Jenis Kelamin

\begin{tabular}{|c|c|c|}
\hline & \\
\hline JENTS KELAIIII & FREKTEISI & PERSENTASE \\
\hline Laki-Laki & 36 & $48 \%$ \\
\hline Perempuad & 30 & $52 \%$ \\
\hline Total & 75 & $100 \%$ \\
\hline \multicolumn{3}{|l}{} \\
\hline
\end{tabular}

Tabel 6. Karakteristik Berdasarkan Jenis Usia

\begin{tabular}{|c|c|c|}
\hline \multicolumn{3}{|c|}{ Jenis Usia } \\
\hline ISLA & FREKLENSI & PERSENTASE \\
\hline 18-25 Tahun & 10 & $13.3 \%$ \\
\hline 26-32 Tahun & 13 & $17.3 \%$ \\
\hline $33-41$ Tahun & 24 & $32 \%$ \\
\hline 42-46 Tahun & 23 & $30.7 \%$ \\
\hline$>46$ Tahun & 5 & $6.7 \%$ \\
\hline Total & 75 & $100 \%$ \\
\hline \multicolumn{3}{|c}{} \\
\hline
\end{tabular}

Tabel 7. Karakteristik Berdasarkan Pengalaman Penggunaan Sistem

\begin{tabular}{|c|c|c|}
\hline $\begin{array}{c}\text { PEIGALAIIAN } \\
\text { PEXGGINAAY SISTEII }\end{array}$ & FREKLENSI & PERSENTASE \\
\hline 〈ITahu & 7 & $9.3 \%$ \\
\hline 1.2 Tabun & 18 & $24 \%$ \\
\hline >2 Tahun & 50 & $66.7 \%$ \\
\hline Total & 75 & $100 \%$ \\
\hline
\end{tabular}

Tabel 8. Karakteristik Berdasarkan Pendidikan Terakhir

\begin{tabular}{|c|c|c|}
\hline $\begin{array}{l}\text { PENDDIKAI } \\
\text { TERAKHIR }\end{array}$ & FREKUENSI & PERSENTASE \\
\hline SILASIIK & 18 & $24 \%$ \\
\hline D3 & 27 & $36 \%$ \\
\hline DASI & 29 & $38.7 \%$ \\
\hline S? & 1 & $1.3 \%$ \\
\hline Total & 75 & $100 \%$ \\
\hline
\end{tabular}

Tabel 9. Karakteristik Berdasarkan Lama Pemakaian Komputer

\begin{tabular}{|c|c|c|}
\hline $\begin{array}{c}\text { L.IIA PEVIKALAI } \\
\text { KOIIPUTER }\end{array}$ & FREKUENSI & PERSENTASE \\
\hline$<1 \mathrm{Jam}$ & 1 & $1.3 \%$ \\
\hline $2.5 \mathrm{Jam}$ & 5 & $6.7 \%$ \\
\hline $6.10 \mathrm{Jam}$ & 67 & $89.3 \%$ \\
\hline$>10 \mathrm{Jam}$ & 2 & $27 \%$ \\
\hline Total & 75 & $100 \%$ \\
\hline
\end{tabular}


Tabel 10. Karakteristik Berdasarkan Lama Unit Kerja

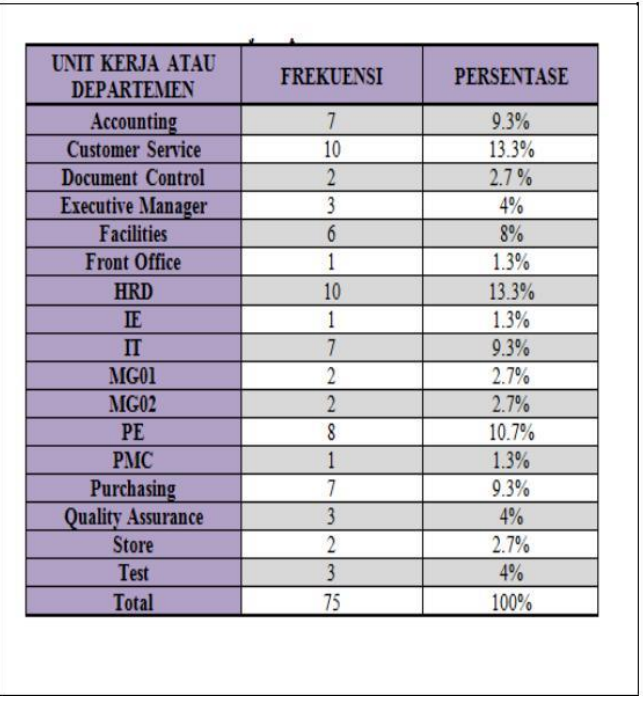

\section{b. Statistik Inferensial}

Menurut Sugiyono (2008) statistik inferensial adalah teknik statistik yang digunakan untuk menganalisis data sampel dan hasilnya diberlakukan untuk populasi. Penelitian ini menggunakan analisis jalur (path analysis) dan pengolahan data penelitian ini dibantu oleh SPSS.

\section{HASIL PENELITIAN}

\section{A. Gambaran Umum Perusahaan}

PT Unisem bergerak dibidang usaha perakitan (assembling), pengujian (testing), dan pengemasan (packing) integrated circuit (IC).Produk-produk yang dihasilkan PT Unisem Batam dibuat berdasarkan pesanan dari pelanggan.Oleh karena itu, PT Unisem Batam disebut perusahaan subkontraktor. Produkproduk yang dihasilkan PT Unisem Batam 100\% dipasarkan ke luar negeri (100\% ekspor).

PT Unisem memiliki beberapa pabrik yang diantaranya berlokasi di Ipoh, Malaysia; Wales, Inggris; Chengdu, Republik Rakyat China (RRC) Sunnyvale, Amerika Serikat dan Batam, Indonesia. Pusat dari PT. Unisem sendiri memiliki cabang

\section{B. PEMBAHASAN}

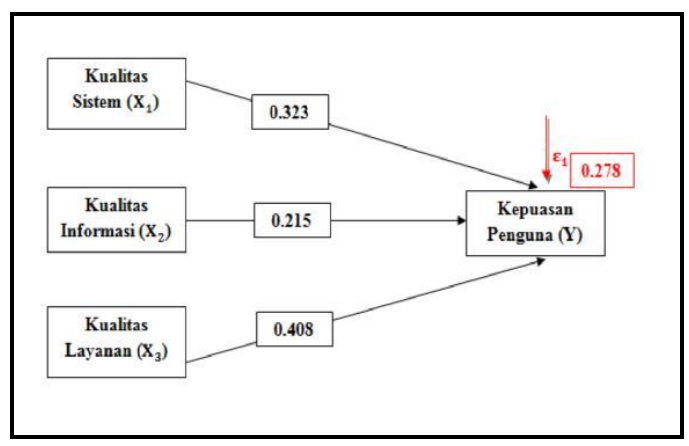

Gambar 3. Hasil Analisis Jalur Pertama

\section{Pengaruh Variabel Kualitas Sistem Infomasi $\left(\mathrm{X}_{1}\right)$ Enterprise Resource Planning (ERP) AIMS/PORTAL di PT UNISEM Terhadap Kepuasan Pengguna (Y)}

Berdasarkan analisis statistik inferensial dengan analisis jalur, terbukti bahwa pengujian hipotesis 1 diterima dan berdasarkan statistik deskriptif mean variabel kualitas sistem informasi berada pada daerah positif atau baik 3.21. Hal ini membuktikan bahwa pengukuran tingkat kesuksesan kualitas sistem informasi dari AIMS/PORTAL di PT UNISEM sudah baik bahkan dapat mempengaruhi kepuasan pengguna sistem AIMS/PORTAL di PT UNISEM, karena sistem yang digunakan dapat menunjang kebutuhan pekerjaan pengguna. Karena, suatu sistem yang baik adalah apabila penggunaan nya dapat berinteraksi dengan baik oleh pengguna dan dapat mengantarkan pengguna dalam mencapai suatu tujuan yang diharapkan.

Pernyataan ini juga diperkuat oleh Rochaety, et al. (2012) yang menjelaskan bahwa sistem yang baik adalah sistem yang mempunyai satu kesatuan yang terdiri dari dua atau lebih komponenn atau subsistem yang berinteraksi untuk mencapai suatu tujuan dan Rochaety, et al. juga (2012) juga memaparkan bahwa sistem yang baik menjalankan mekanisme penggunaan mulai dari peng-input-an data melewati proses atau suatu transformasi lalu menghasilkan sebuah output yang dibutuhkan oleh pengguna. 
Kiki \&Shinta, mengukur kesuksesan penggunaan sistem informasi enterprise resources planning (erp) ...

\section{Pengaruh Variabel Kualitas Infomasi} $\left(\mathrm{X}_{2}\right)$ Enterprise Resource Planning (ERP) AIMS/PORTAL di PT UNISEM Terhadap Kepuasan Pengguna (Y)

Berdasarkan analisis statistik inferensial dengan analisis jalur, terbukti bahwa pengujian hipotesis 2 diterima dan berdasarkan statistik deskriptif mean variabel kualitas informasi berada pada daerah positif atau cukup baik 3.02.

Kualitas Informasi yang diberikan oleh sistem AIMS/PORTAL oleh pengguna sudah cukup baik, karena memberikan informasi yang relevansi, mudah dimengerti, informasi yang akurat, kelengkapan informasi, dan menghasilkan informasi yang bernilai guna dan up to date. Informasi merupakan data yang telah diproses kedalam suatu bentuk yang mempunyai arti bagi penerima dan memiliki nilai nyata yang dibutuhkan untuk proses pengambilan kepuusan saat ini maupun saat mendatang Rochaety et al (2012) dalam penelitian (Gordon B. Davis.)

\section{Pengaruh Variabel Kualitas Layanan} $\left(\mathrm{X}_{3}\right)$ Enterprise Resource Planning (ERP) AIMS/PORTAL di PT UNISEM Terhadap Kepuasan Pengguna (Y)

Berdasarkan analisis statistik inferensial dengan analisis jalur, terbukti bahwa pengujian hipotesis 3 diterima dan berdasarkan statistik deskriptif mean variabel kualitas layanan berada pada daerah positif atau cukup baik 3.20.

Staff IT (Information Technology) yang ditunjuk langsung oleh pimpinan sebagai pengelola atau penggerak utama dari sistem AIMS/PORTAL menurut responden sudah menjalankan tugasnya dengan baik yang terdiri dari memberikan pelayanan jika terdapat masalah yang tidak data diatasi secara langsung oleh pengguna, hal ini dapat dilihat dari daya tangga staff IT yang sudah cekatan memberikan pelayanan kepada pengguna sistem informasi di PT UNISEM, empati, trouble shooting yang dilakukan untuk membantu pengguna yang menemui kendala dalam pemakaian sistem AIMS/PORTAL yang mengalami kendala sudah cukup baik, tapi kualitas layanan yang diberikan oleh staff IT harus mendapat beberapa perubahan untuk meningkatkan kepuasan pengguna, karena beberapa diantaranya ada pengguna yang tidak terlalu puas dengan pelayanan yang dilakukan oleh staff IT.

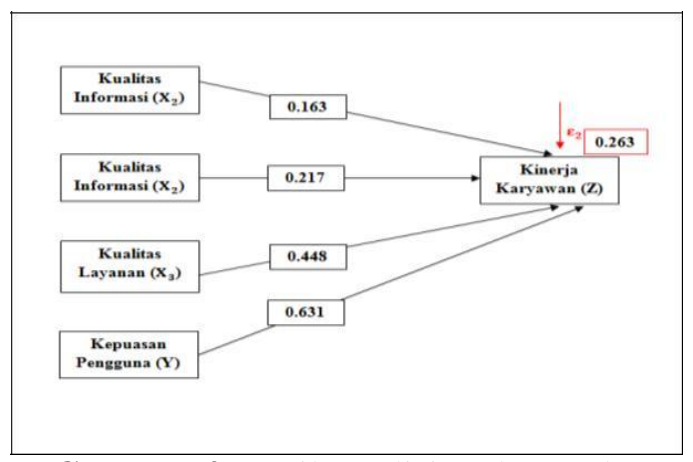

Gambar 4. Hasil Analisis Jalur Kedua

4. Pengaruh Variabel Kualitas Sistem Informasi $\left(\mathrm{X}_{1}\right)$ Enterprise Resource Planning (ERP) AIMS/PORTAL di PT UNISEM Terhadap Kinerja Karyawan (Z)

Berdasarkan analisis statistik inferensial dengan analisis jalur, terbukti bahwa pengujian hipotesis 4 diterima dan berdasarkan statistik deskriptif mean variabel kualitas sistem berada pada daerah positif atau cukup baik 3.21. Hal ini menunjukkan adanya hubungan yang signifikan antara variabel kualitas sistem informasi dengan kinerja karyawan.

Karakteristik yang diinginkan dari suatu informasi sistem. Misalnya, kemudahan penggunaan, fleksibilitas sistem, sistem kehandalan, dan kemudahan belajar, serta fitur sistem intuitif, kecanggihan, fleksibilitas, dan waktu kecepatan beberapa item ini telah diberikan dalam sistem AIMS/PORTAL untuk menunjang kinerja karyawan sehingga penelitian yang dilakukan hasil nya menunjukkan bahwa antara kualitas sistem informasi sangat berpengaruh untuk meningkatkan kenerja karyawan.

Pernyataan ini diperkuat oleh hasil penelitian yang menyatakan bahwa Sejauh mana sistem informasi yang berkontribusi atau tidak memberikan kontribusi untuk 
memberikan keberhasilan individu, kelompok, organisasi, industri, dan negara. Peningkatan pengambilan keputusan, peningkatan produktivitas, peningkatan penjualan, pengurangan biaya, keuntungan meningkat, efisiensi pasar, konsumen kesejahteraan, penciptaan lapangan kerja, dan pembangunan ekonomi.

Aplikasi praktis dari D \& M Model (2003) seperti yang dijelaskan sebelumnya adalah tergantung pada konteks organisasi. Pemilihan dimensi keberhasilan tertentu dan metrik tertentu tergantung pada sifat dan tujuan dari organisasi ataupun perusahaan tersebut, dimana sifat diciptakannya sistem AIMS/PORTAL ini untuk media meningkatkan kualitas dan kuantitas kienerja karyawan di PT UNISEM.

\section{Pengaruh Variabel Kualitas Informasi} $\left(\mathrm{X}_{2}\right)$ Enterprise Resource Planning (ERP) AIMS/PORTAL di PT UNISEM Terhadap Kinerja Karyawan (Z)

Berdasarkan analisis statistik inferensial dengan analisis jalur, terbukti bahwa pengujian hipotesis 5 diterima dan berdasarkan statistik deskriptif mean variabel kualitas informasi berada pada daerah positif atau cukup baik 3.02.

Artinya bahwa kualitas informasi mempunyai pengaruh yang baik untuk meningkatkan kinerja karyawan. Karena, apabila informasi yang dihasilkan tepat, akurat untuk output yang dihasilkan oleh karyawan, maka hal ini akan memudahkan kinerja karyawan.

Pernyataan ini diperkuat oleh teori faktor-faktor yang mempengaruhi kinerja karyawan dalam suatu organisasi menurut Prawirosentono dalam Sutrisno (2011) bahwa salah satu faktor yang mempengaruhi kinerja karyawan adalah Efektifitas dan efisien dikatakan efektif bila mencapai tujuan, dimana kualitas informasi yang diterapkan di PT UNISEM sudah sesuai dengan tujuan walau belum mencakup semua karena masih ada beberapa fitur-fitur yang belum di buat dalam sistem AIMS/PORTAL dan dikatakan efisien bila hal itu memuaskan sebagai pendorong mencapai tujuan, terlepas apakah efektif atau tidak.

\section{Pengaruh Variabel Kualitas Layanan $\left(\mathrm{X}_{3}\right)$ Enterprise Resource Planning (ERP) UNISEM Terhadap Kinerja Karyawan (Z)}

Berdasarkan analisis statistik inferensial dengan analisis jalur, terbukti bahwa pengujian hipotesis 6 diterima dan berdasarkan statistik deskriptif mean variabel kualitas layanan berada pada daerah positif atau cukup baik 3.21.

Artinya kualitas layanan yang telah diberikan oleh staff IT sudah cukup baik untuk menunjang kinerja karyawan di PT UNISEM, tapi hal ini belum sepenuhnya dirasakan oleh karyawan yang mengalami kendala saat menggunakan sistem, karena ketika staff IT di butuhkan beberapa karyawan harus masih menunggu, karena staff IT masih memperbaiki masalah sistem yang lain. Hal ini tentunya menjadi kendala bagi karyawan untuk menyelesaikan target yang dibuat sebelumnya.

Untuk itu agar kinerja karyawan tetap terus berjalan dan sesuai target perlu ada nya penambahan karyawan agar kualias layanan bisa menjadi sangat baik dan merata roachaety, et.al (2006) guna menunjang kinerja karyawan di PT UNISEM.

7. Pengaruh Variabel Kepuasan Pengguna (Y) Enterprise Resource Planning (ERP) AIMS/PORTAL di PT UNISEM Terhadap Kinerja Karyawan (Z)

Berdasarkan analisis statistik inferensial dengan analisis jalur, terbukti bahwa pengujian hipotesis 7 diterima dan berdasarkan statistik deskriptif mean variabel kepuasan pengguna berada pada daerah positif atau cukup baik 3.19.

Kesimpulan ini diperkuat dalam penelitian Istianingsih dan Utami (2010) yang mengadopsi teori DeLone \& McLean, Davis, dan Seddon, menyatakan bahwa dampak pemakaian suatu sistem informasi terhadap individu pengguna(individual impact) didefinisikan sebagai tingkat dimana seseorang percaya bahwa dengan 
Kiki \&Shinta, mengukur kesuksesan penggunaan sistem informasi enterprise resources planning (erp) ...

menggunakan sistem tertentu dapat meningkatkan kinerjanya.

\section{Pengaruh Variabel Kualitas Sistem} Informasi $\left(\mathrm{X}_{1}\right)$, Kualitas Informasi $\left(\mathrm{X}_{2}\right)$, Kualitas Informasi $\left(\mathbf{X}_{\mathbf{3}}\right)$, Terhadap Kepuasan Pengguna (Y) dan Dampaknya pada Kinerja Karyawan di PT UNISEM (Z)

Berdasarkan analisis statistik inferensial dengan analisis jalur, terbukti bahwa pengujian hipotesis 8 diterima. Kualitas sistem, kualitas informasi, kualitas layanan merupakan indikator yang harus di perhatikan dalam penerapan sistem Enterprise Resource Planning terutama di PT UNISEM yang menerapkan sistem ERP yaitu AIMS/PORTAL karena, jika ketiga indikator tersebut menunjukkan kualitas yang sangat baik dapat menciptakan kepuasan pengguna dan berdampak pada kinerja karyawan.

Dalam penenlitian ini terbukti bahwa kualitas sistem, kualitas informasi, dan kualitas layanan mempunyai pengaruh yang simultan atau secara bersama-sama memberikan pengaruh terhadap kepuasan pengguna sistem dan juga berdampak pada kinerja karyawan. Pencapaian perusahaan secara maksimal akan terwujud apabila kebutuhan yang diberikan perusahaan untuk menunjang pekerjaaan di penuhi bahkan melebihi ekspetasi pengguna sistem untuk meberikan rasa nyaman pengguna pada saat melakukan tugas dan tanggung jawab untuk mencapai visi dan misi perusahaan.

Livari (2006), juga melakukan penelitian mengenai keberhasilan sistem informasi yang baru diterapkan terhadap pengguna sistem informasi di satu organisasi yang bersifat mandatory. Hasil penelitiannya untuk hubungan variabel individual impact dengan user satisfaction menunjukkan adanya pengaruh positif dari kedua variable tersebut dengan aspek.

\section{SIMPULAN}

Terdapat pengaruh langsung yang signifikan dari kualitas sistem informasi terhadap kepuasan pengguna. Hal ini dibuktikan dari nilai $\mathrm{t}$ hitung $=3.131$ yang lebih besar dari t tabel $=1.99444$ atau nilai $\operatorname{sig} \mathrm{t}=0.003$ yang lebih kecil dari $\alpha=0.05$.
Begitu juga dengan kualitas informasi mempunyai pengaruh langsung yang signifikan terhadap kepuasan pengguna. Hal ini dibuktikan dari nilai $\mathrm{t}$ hitung $=2.023$ yang lebih besar dari $t$ tabel $=1.99444$ atau nilai sig $\mathrm{t}=0.047$ yang lebih kecil dari $\alpha=$ 0.05 . sama halnya dengan kualitas sistem informasi dan kualitas sistem informasi, terdapat pengaruh langsung yang signifikan dari kualitas layanan terhadap kepuasan pengguna. Hal ini dibuktikan dari nilai $\mathrm{t}$ hitung $=4.507$ yang lebih besar dari t tabel $=1.99444$ atau nilai sig $\mathrm{t}=0.000$ yang lebih kecil dari $\alpha=0.05$. Jadi dapat disimpulkan, kualitas sistem informasi, kualitas informasi dan kualitas layanan berpengaruh terhadap kepuasan pengguna sistem enterprise resource planning yang diberi nama AIMS dan PORTAL di PT UNISEM.

Dalam penelitian ini juga terdapat pengaruh langsung yang signifikan dari kualitas sistem informasi terhadap kinerja karyawan. Hal ini dibuktikan dari nilai $\mathrm{t}$ hitung $=2.620$ yang lebih besar dari t tabel $=1.99444$ atau nilai sig $\mathrm{t}=0.011$ yang lebih kecil dari $\alpha=0.05$. Begitu juga dengan kualitas informasi mempunyai pengaruh langsung yang signifikan terhadap kinerja karyawan. Hal ini dibuktikan dari nilai $\mathrm{t}$ hitung $=2.222$ yang lebih besar dari $t$ tabel $=1.99444$ atau nilai sig $\mathrm{t}=0.030$ yang lebih kecil dari $\alpha=0.05$. sama halnya dengan kualitas sistem informasi dan kualitas sistem informasi, terdapat pengaruh langsung yang signifikan dari kualitas layanan terhadap kinerja karyawan. Hal ini dibuktikan dari nilai thitung $=4.123$ yang lebih besar dari $\mathrm{t}$ tabel $=1.99444$ atau nilai sig $\mathrm{t}=0.000$ yang lebih kecil dari $\alpha=0.05$. Serta dalam penelitian ini, terdapat pengaruh langsung yang signifikan dari variabel kepuasan pengguna terhadap kinerja karyawan. Hal ini dibuktikan dari nilai $\mathrm{t}$ hitung $=7.291$ yang lebih besar dari $t$ tabel $=1.99444$ atau nilai sig $\mathrm{t}=0.000$ yang lebih kecil dari $\alpha=$ 0.05 .

Jadi dapat disimpulkan, kualitas sistem informasi, kualitas informasi, kualitas layanan dan kepuasan pengguna berpengaruh terhadap kinerja karyawan dalam menjalankan sistem enterprise resource planning yang diberi nama AIMS dan PORTAL di PT UNISEM. 
Tidak hanya itu, dalam penelitian ini juga menghasilkan pengaruh secara simultan yang signifikan dari kualitas sistem informasi, kualitas informasi, kualitas layanan dan kepuasan pengguna terhadap kinerja karyawan dengan menggunakan teknik analisis jalur. Hal ini dibuktikan dengan tingka signifikansi 0.001. Diperoleh nilai $\mathrm{F}$ Hitung 49.105 dan $\mathrm{F}$ tabel $=2.50$. Jadi dapat disimpulkan, kualitas sistem informasi, kualitas informasi, dan kualitas layanan berengaruh secara signifikan terhadap kepuasan pengguna sehingga berdampak pada kinerja karyawan di PT UNISEM.

\section{SARAN}

Kualitas sistem informasi yang diterapkan di PT UNISEM sudah optimal. Tetapihendaknya dalam sistem informasi AIMS/PORTAL di lakukan pembaharuan versi agar proses sistem nya menjadi lebih cepat dan agar terkoneksi dengan baik, serta di unit kerja atau bagian yang menggunakan sistem AIMS/PORTAL yang fitur nya belum terhubung antar unit satu dengan unit lain yang saling terkait untuk menambahkan beberapa fiturnya agar penerapan paper less di PT UNISEM benar-benar terlaksana. Kualitas informasi yang diterapkan PT UNISEM sudah menghasilkan input dan output yang dibutuhkan oleh pengguna dan sesuai dengan standar yang ditetapkan perusahaan dalam menunjang proses bisnis pendukung perusahaan dan hal ini sudah cukup baik. Tetapi, hendaknya informasi yang diberikan mudah dipahami untuk itu yang perlu di perhatikan adalah tata letak dari tampilan output yang dihasilkan, agar semua pihak dapat memahami dengan baik. Diperlukan adanya sosialisasi output atau data yang dihasilkan agar tidak terjadi kesalahan masukan data dari pengguna.

Kualitas layanan sistem yan diberikan oleh petugas atau staff IT sudah baik kepada para pengguna sistem AIMS/PORTAL hanya saja penanganan yang diberikan kurang cekatan atau cepat, karena keterbatasan personil di bagian IT. Oleh sebab itu, diperlukan adanya penambahan sumber daya manusia dibagian unit kerka IT.
Mengingat PT UNISEM proses bisnis lebih banyak menggunakan sistem, sementara tidak sebanding dengan personil yang ada di lapangan, sehingga keterlambatan dalam penangan kepada pengguna yang mengalami hambatan atau terdapat masalah dalam penggunaan sistem pun terjadi. Kepuasan pengguna, perusahaan harus memberikan perhatian lebih bagaimana cara meningkatkan lagi tingkat kepuasan pengguna dalam pemakaian AIMS/PORTAL.

Karena kepuasan pengguna yang tinggi tentunya juga menjadi faktor yang meningkatkan kinerja karyawan. Kepuasan pengguna ini bisa di peroleh dari tampilan yang lebih menarik atau tidak membosan dari sistem AIMS/PORTAL.

\section{DAFTAR PUSTAKA}

Babu, T. K. S., dan Dalal, S. S. (2006). ERP Implementation Issues in SMEs: Microsoft Great Plains' Implementation in a BPO Organization. South Asian Journal of Management 13 (1) ProQuest.

Edlund, S dan Lovquist, A. (2012). The Role of System Administrator in Information System Succes,[Master Thesis], Dept. Business Study Uppsla.

Gable, G., Sedera, D., and Chan, T. (2008), Reconceptualizing Information System Success: the IS-Impact Measurement Model, Journal of the Association for Information Systems. 9 (7), pp. 377-408.

Hasan, Y., et.al., (2013). The Impact of Management Information Systems Adoption in Managerial Decision Making: A Review. Management Information Systems, 8 (4), pp. 010-017.

Hati, S.W., dan Nurhayani, S., (2016). Pengelolaan Arsip Elektronik Terhadap Efisiensi Kinerja Karyawan Bagian Staff Kantor Pada PT ABC Di Batam. Jurnal Inovasi dan Bisnis, 4 (1), hlm. 69-79.

Iranto, B. D., dan Januarti, I., (2013). Pengaruh Kepuasan Pengguna Sistem Informasi Terhadap Kinerja Individu. 
Kiki \&Shinta, mengukur kesuksesan penggunaan sistem informasi enterprise resources planning (erp) ...

Istianingsih dan Wijanto, S. H., 2008. Pengaruh Kualitas Sistem informasi, Kualitas Informasi, dan Percived Usefulness Terhadap Kepuasan Pengguna Software Akuntansi. Simposium Nasional Akuntansi IX, Pontianak. Mc.Leod dan P.Schell. (2008). Sistem Informasi Manajemen. (Edisi 10). Jakarta : Sad lemba Empat.

Moon, Y. B. 2007. Enterprise Resource Planning (ERP): A review of the literature. International Journal Management and Enterprise Development, 4 (3), pp. 235 264.

Petter, S., DeLone, W., and McLean, E. (2008), Measuring Information Systems Success: Models, Dimensions, Measures, and Interrelationships, Euro-pean Journal of Information Systems, (17), pp. 236-263.

Robey, D. G. Im, dan J. D. Wareham. (2009) Theoretical foundations of empirical research on interorganizational systems: Assessing past contributions and guiding future directions. Journal of the Association for Information Systems, 9(9), pp. 497-518.

Rochaety, et al. (2013). Sistem Informasi Manajemen. (Edisi 2). Jakarta : Mitra Wacana Media.

Samwel, M., dan Ogao, P., (2013) Enterprise

Resource Planning (ERP) System Implementation: A case for User participation. Procedia Technology, (9), pp. 75-120.

Sugiyono, (2006). Metode Penelitian Kuantitatif Kualitatif dan Penelitian Pengembangan. Bandung: Alfabeta.

Sugiyono, (2008). Metode Penelitian Kuantitatif Kualitatif dan Penelitian Pengembangan. Bandung:Alfabeta.

Sugiyono. (2015). "Metode Penelitian Kuantitatif, Kualitatif, Dan R\&D”. Bandung:Alfabeta.

Sujadi, S. W. (2012). Perancangan Penilaian Kinerja Pegawai Berdasarkan Kompetensi Spencer. Jurnal STIE Semarang, 4(1).
Wu, J.H. dan Wang, Y.M. (2006). Measuring KMS success: a respecification of the DeLone and McLean model. Information \& Management 43 